\title{
Hamilton-Jacobi Equations on an almost Kähler Model of a Cartan Space
}

\author{
Ahmet MOLLAOĞULLARI ${ }^{1}$, Mehmet TEKKOYUN ${ }^{2}$ \\ ${ }^{1}$ Çanakkale Onsekiz Mart Üniversitesi, Fen Edebiyat Fakültesi, Matemetik Bölümü, Çanakkale. \\ ${ }^{2}$ Çanakkale Onsekiz Mart Üniversitesi, iktisadi ve idari Bilimler Fakültesi, İşletme Bölümü, Çanakkale.. \\ e-posta:ahmet_m@comu.edu.tr, tekkoyun@comu.edu.tr
}

Geliş Tarihi:29.05.2015; Kabul Tarihi:23.12.2015

\begin{tabular}{cl}
$\begin{array}{c}\text { Keywords } \\
\text { Cartan Manifold; }\end{array}$ & Özet \\
\cline { 2 - 2 } $\begin{array}{c}\text { Kahler Manifold; } \\
\text { As known, Hamiltonian models arise to be a very important tool in modern geometry. Because they } \\
\text { Hamiltonian }\end{array}$ & $\begin{array}{l}\text { present a simple method to describe the different model for mechanical systems. Therefore in this } \\
\text { mechanics; }\end{array}$ \\
$\begin{array}{c}\text { Hamilton-Jacobi } \\
\text { this model. In the conclusion we discuss some results about related mechanical system. }\end{array}$ \\
\end{tabular}

\section{Bir Cartan Uzayının Hemen Hemen Kähler Modeli Üzerindeki Hamilton-Jakobi Denklemleri}

\author{
Anahtar kelimeler \\ Cartan manifoldu; \\ Kahler Manifoldu; \\ Hamilton Mekaniği; \\ Hamilton-Jakobi \\ Denklemleri
}

\begin{abstract}
Bilindiği üzere Hamilton modelleri modern geometride giderek önem kazanmaktadır. Çünkü bu modeller mekanik sistemlerin farklı modellerini tasvir etmek için daha kolay bir yöntem sağlamaktadır . Bundan dolayı çalışmada bahsi geçen model kullanılarak Bir Cartan Uzayının Hemen Hemen Kähler modeli üzerinde Hamilton-Jakobi hareket denklemlerini elde edilmiştir. Sonuç kısmında ise ilgili mekanik sistemler üzerinde elde edilen bulgular tartışılmıştır.
\end{abstract}

(C) Afyon Kocatepe Üniversitesi

\section{Introduction}

Hamiltonian mechanics uses the fundamental structures of modern differential geometry. Because a suitable vector field on a cotangent space which is the phase space of momentum of a given configuration space explains the dynamics of Hamiltonians. These dynamics formalisms and Hamilton equations are set as follows:

Let $M$ is $m$-dimensional configyration manifold and its cotangent bundle $T^{*} M$. If $H: T^{*} M \rightarrow \mathbb{R}$ is a regular Hamiltonian function then there is a unique vector field $\mathrm{X}_{\mathrm{H}}$ on $\mathrm{T}^{*} \mathrm{M}$ such that Hamiltonian dynamical formalism

$$
i_{\mathrm{X}_{\mathrm{H}}} \phi=d H
$$

where $\phi$ is the canonical symplectic form so that $\phi=-d \lambda, \lambda=J^{*}(\omega), J^{*}$ a dual of $J, \omega$ a 1 -form on $T^{*} M$. Further, the geodesies of the manifold $\mathrm{M}$ can be found by solving Hamiltonian equations shown by

$$
\frac{d x^{i}}{d t}=\frac{\partial H}{\partial p_{i}}, \quad \frac{d p_{i}}{d t}=-\frac{\partial H}{\partial x^{i}}
$$

where $\left(x^{i}\right)$ and $\left(x^{i}, p_{i}\right), 1 \leq i \leq m$, are coordiantes of $\mathrm{M}$ and $\mathrm{T}^{*} \mathrm{M}$ respectively. Furthermore the triple $\left(\mathrm{T}^{*} \mathrm{M}, \phi, \mathrm{X}_{\mathrm{H}}\right)$ is called Hamiltonian system on $\mathrm{T}^{*} \mathrm{M}$ (de Leon and Rodrigues, 1989; Miron et al, 2001). It is possible to find many studies about Hamiltonian mechanics, dynamics and equations in articles (Tekkoyun and Yaylı, 2011; Tekkoyun and Celik 2013; Klein, 1963) and in books (de Leon and Rogrigues, 1985). 
Hamilton-Jacobi equations (HJE) have also been an interesting area for mathematicians and physicists. Since they have many applications in physics, the solutions of these equations are investigated in many papers.

Crandall et al. studied viscosity solutions of HJE, also Xuehong Zhu presented viscosity solutions of HJE on Riemannian manifolds which make the probabilistic interpretation for nonlinear PDEs on Riemannian manifolds (Crandall and Lions, 1983; Zhu, 2014) P. L. Lions, G. Papanicolaou and S. R. S. Varadhan are concerned with homogenization of HJE in their paper (Lions at al., unpublished). P. Jameson Graber showed the optimal control of solutions of first order Hamilton-Jacobi equations, where the Hamiltonian is convex with linear growth (Graber, 2014).

In this study, we set Hamilton-Jacobi equations on an almost Kähler model of a Cartan manifold. In the

conclusion we say some results about related mechanical system and equations.

\section{Cartan Structure and Almost Kähler Model of a Cartan Space}

In this section we remind of some structures given by Riron and Rodrigues (2001). Let $\mathrm{M}$ a smooth manifold of real dimension $\mathrm{m}$ and $K: T^{*} M \rightarrow[0, \infty]$ is a real function. Then the pair $\left(C^{n}, K(x, p)\right)$ is aCartan space if the following axioms hold:

i) $\mathrm{K}$ is differentiable on $\mathrm{T}^{*} \mathrm{M} \backslash\{0\}$ for

$\{0\}=$ $\{(x, 0) \mid x \in M\}$

ii) $\mathrm{K}$ is positively 1-homogeneous on the fibres of cotangent bundle $\mathrm{T}^{*} \mathrm{M}$ that is $K(x, \lambda p)=\lambda K(x, p)$ for all $\lambda>0$

iii) The Hessian of $K^{2}$ with elements

$$
g^{i j}(x, p)=\frac{1}{2} \frac{\partial K^{2}}{\partial p_{i} \partial p_{j}}
$$

is positively defined on $\mathrm{T}^{*} \mathrm{M} \backslash\{0\}$.

It can be seen that $g^{i j}$ is symmetric and nonsingular distinguished tensor field (d-tensor field) and contravariant of order 2 on the manifold
$\mathrm{T}^{*} \mathrm{M} \backslash\{0\}$. The function $K(x, p)$ is called fundemental function and the d-tensor field $g^{i j}$ is called fundemental (or metric) tensor of the Cartan Space $C^{n}=(M, K(x, p))$. A Cartan space $C^{n}=$ $(M, K)$ can be thought as an almost Kähler space on the manifold $\mathrm{T}^{*} \mathrm{M} \backslash\{0\}$, called the geometrical model of the Cartan space. Considering nonlinear connection $N_{i}^{j}$ on $\mathrm{T}^{*} \mathrm{M}$ with $N: u \in T^{*} M \mapsto N_{u} \subset$ $T_{u} T^{*} M \quad$ then we can write $T_{u} T^{*} M=$ $H_{u} T^{*} M \oplus V_{u} T^{*} M$ for all $u \in \mathrm{T}^{*} \mathrm{M}$ where $\mathrm{H}$ and $\mathrm{V}$ are horizontal and vertical distributions respectively. Afterwards it fallows that

$$
\begin{gathered}
\left(\frac{\partial}{\partial x^{i}}\right)^{H}=\frac{\delta}{\delta x^{i}}=\frac{\partial}{\partial x^{i}}-N_{i}^{j}(x, p) \frac{\partial}{\partial p_{i}} \\
\left(\frac{\partial}{\partial p_{i}}\right)^{V}=\frac{\partial}{\partial p_{i}}
\end{gathered}
$$

Morever $\left(\frac{\delta}{\delta x^{i}}\right), i=1, \ldots, m$ is a local base in HTM, $\left(\frac{\delta}{\delta x^{i}}, \frac{\partial}{\partial p_{i}}\right) i=1, \ldots, m$ is a local base adapted to the HTM and VTM. And also $\left(d x^{i}, \delta p_{i}\right) i=1, \ldots, m$ is the dual base of $\left(\frac{\delta}{\delta x^{i}}, \frac{\partial}{\partial p_{i}}\right) i=1, \ldots, m \quad$ where $\quad \delta p_{i}=d x^{i}+$ $N_{i}^{j}(x, p) d p_{i} \in H T^{*} M$. Suppose that the d-tensor metric $g^{i j}(x, p)$ and the symmetric nonlinear connection $\mathrm{N}$ are given then we can define almost complex structure $\mathbf{F}$ as follows:

$$
\boldsymbol{F}\left(\frac{\partial}{\partial x^{i}}\right)=-g_{i j} \frac{\partial}{\partial p_{i}} \quad \boldsymbol{F}\left(\frac{\partial}{\partial p_{i}}\right)=g^{i j} \frac{\delta}{\delta x^{i}}
$$

Then the affect of $\boldsymbol{F}$ on the base $\left(d x^{i}, \delta p_{i}\right)$ as follows:

$$
\boldsymbol{F}^{*}\left(d x^{i}\right)=-g_{i j} \delta p_{i} \quad \boldsymbol{F}^{*}\left(\delta p_{i}\right)=g^{i j} d x^{i}
$$

The $\mathrm{N}$-lift of the tensor field $g^{i j}$ of $C^{n}$ can be introduced as follows:

$$
\boldsymbol{G}=g_{i j} d x^{i} \otimes d x^{j}+g^{i j} \delta p_{i} \otimes \delta p_{j}
$$

Consequently, $\mathbf{G}$ is a Riemann metric on $\mathrm{T}^{*} \mathrm{M} \backslash\{0\}$ determined only by the fundemental function $\mathrm{K}$ of the space $C^{n}$ and the horizantal and vertical distributions are orthogonal with respect to it.

Thoerem 1. (Miron et al, 2001) 
i) The pair $\left(G, F^{*}\right)$ is an almost Hermitian structure on $\mathrm{T}^{*} \mathrm{M}$

ii)The almost symplectic 2-form associated to the almost Hermitian structure $\left(\mathrm{G}, \mathrm{F}^{*}\right)$ is

$$
\theta=\delta p_{i} \wedge d x^{i}
$$

iii) The space $H^{2 m}=\left(T^{*} M \backslash\{0\}, \boldsymbol{G}, \boldsymbol{F}^{*}\right)$ is an almost Kahler space, constructed only by means of fundemental function $\mathrm{K}$ of the space $C^{n}$.

Definition 1.: The space $H^{2 m}=\left(T^{*} M \backslash\{0\}, \boldsymbol{G}, \boldsymbol{F}^{*}\right)$ is called almost Kahler model of the space $C^{n}$

\section{Hamilton-Jacobi Equations}

Here we present Hamilton-Jacobi equations and Hamiltonian mechanical systems for quantum and classical mechanics constructed on the almost Kahler model $H^{* 2 m}=\left(T^{*} M \backslash\{0\}, \boldsymbol{G}, \boldsymbol{F}^{*}\right)$ of the space $C^{n}$

Theorem 2. (Miron et al, 2001)

There exists a unique vector field $X_{K^{2}} \in \chi\left(T^{*} M \backslash\right.$ $\{0\}$ ) with the property

$$
i_{X_{K^{2}}} \phi=-d K^{2}
$$

for ant Cartan space. This equation is called Hamilton-Jacobi formalism.

Now, firstly let set a 1 -form

$$
\begin{aligned}
& g_{i j} d x^{i} \otimes d x^{j}+g^{i j} \delta p_{i} \otimes \delta p_{j} \\
& \omega=\frac{1}{2} g^{i j} x^{i} d x^{i}+\frac{1}{2} g_{i j} p_{i} \delta p_{i}
\end{aligned}
$$

Then we have the Lioville form

$$
\lambda=\boldsymbol{F}^{*}(\omega)=-\frac{1}{2} x^{i} \delta p_{i}+\frac{1}{2} p_{i} d x^{i}
$$

and the closed form

$$
\phi=-d \lambda=d x^{i} \wedge \delta p_{i}
$$

Set Hamiltonian vector field as follows:

$$
X_{K^{2}}=X^{i} \frac{\partial}{\partial x^{i}}+Y^{i} \frac{\delta}{\delta p_{i}}
$$

Then we find

$$
i_{X_{K^{2}}} \phi=\phi\left(X_{K^{2}}\right)=X^{i} \delta p_{i}-Y^{i} d x^{i}
$$

and

$$
-d K^{2}=-\frac{\delta K^{2}}{\delta x^{i}} d x^{i}-\frac{\partial K^{2}}{\partial p_{i}} \delta p_{i}
$$

By means of (10), then the Hamiltonian vector field $X_{K^{2}}$ is found as follows:

$$
X_{K^{2}}=-\frac{\partial K^{2}}{\partial p_{i}} \frac{\partial}{\partial x^{i}}+\frac{\delta K^{2}}{\delta x^{i}} \frac{\delta}{\delta p_{i}}
$$

Assume that a curve

$$
\alpha: I \subset \mathbb{R} \rightarrow T^{*} M \backslash\{0\}
$$

be an integral curve of the Hamiltonian vector field $X_{K^{2}}$, i.e.,

$$
X_{K^{2}}(\alpha(t))=\dot{\alpha}(t)
$$

In the local coordinates, it is obtained that

$$
\alpha(t)=\left(x^{i}, p_{i}\right)
$$

and

$$
\dot{\alpha}(t)=\frac{d x^{i}}{d t} \frac{\partial}{\partial x^{i}}+\frac{d p_{i}}{d t}
$$

Considering (19), (17) and (21) we find

$$
\frac{d x^{i}}{d t}=-\frac{\partial K^{2}}{\partial p_{i}}, \frac{d p_{i}}{d t}=\frac{\delta K^{2}}{\delta x^{i}}
$$

Hence the equations in (22) are named HamiltonJacobi equations on the almost Kahler model $H^{* 2 m}$ of the manifold $C^{n}$. And then the triple $\left(H^{* 2 m}, \phi, X_{K^{2}}\right)$ is said to be a Hamiltonian mechanical system.

\section{Conclusion}

In this study, Hamiltonian mechanical system has intrinsically been described on the almost Kähler model $H^{* 2 m}=\left(T^{*} M \backslash\{0\}, \boldsymbol{G}, \boldsymbol{F}^{*}\right)$ of the Cartan space $C^{n}$. The paths of the Hamilton vector field $X_{K^{2}}$ on the almost Kähler model $H^{* 2 m}$ 
are the solutions of Hamilton -Jacobi equations raised in (22).

Nowadays, as known Hamiltonian models arise to be a very important tool since they present a simple method to describe the model for mechanical systems. One can be proved that the obtained Hamilton-Jacobi equations are very important to explain situations as viscosity, probabilistic interpretation, optimal control, homogenization. Therefore, the found equations are only considered to be a first step to realize how a Hamilton-Jacobi equations have been used in solving problems in different mathematical and physical areas.

\section{References}

de Leon M., Rodrigues P. R., 1989, Methods of differential geometry in analytical mechanics, North-Hol. Math.St.,152, Elsevier Sc. Pub. Com. Inc., Amsterdam.

Miron R., Hrimiuc D., Shimada H., Sabau S. V., 2001, The Geometry of Hamilton and Lagrange spaces, Hingham,MA, USA: Kluwer Academic Publishers.

Tekkoyun M., Yayli Y., 2011, Mechanical systems on generalized-quaternionic Kähler manifolds, IJGMMP, Vol.8, 7, 1-13.

Tekkoyun M., Çelik O., 2013, Mechanical systems on an almost Kähler model of Finsler manifold, International Journal of Geometric Methods in Modern Physics (IJGMMP), Vol. 10, 10, 18-27

de León M., Rodrigues P. R., 1985, Generalized classical mechanics and field theory, NorthHolland Mathematics Studies, North-Holland, Amsterdam.

Crandall M., Lions P. L., 1983, Viscosity solutions of Hamilton-Jacobi equations, Trans.Amer. Math. Soc., 277 , 1-42.
Zhu X., 2014, The optimal control related to Riemannian manifolds and the viscosity solutions to Hamilton- Jacobi-Bellman equations, Systems \& Control Letters , 69, , 7-15

Lions P. L., Papanicolaou G., and Varadhan S. R. S., Homogenization of Hamilton.Jacobi equations, unpublished.

Graber P. J., 2014, Optimal control of first-order Hamilton-Jacobi equations with linearly bounded Hamiltonian, Applied Mathematics \& Optimization, October 2014, 70, 185-224. 